\title{
Ocean Ultrasonic Shear and Compression Viscosities
}

\author{
Josè V. Alemán ${ }^{*}$, , Pablo Sangrà ${ }^{1}$ and Rafael Carbó ${ }^{2}$ \\ ${ }^{I}$ Facultad de Ciencias del Mar, Campus Universitario de Tafira, 35017 Las Palmas de Gran Canaria, Spain \\ ${ }^{2}$ Centro de Tecnologias Fisicas (CSIC),Serrano 144, 28006 Madrid, Spain
}

\begin{abstract}
A comprehensive description of ocean molecular flow and deformation is provided with the help of hydrodynamic and ultrasonic principles. Hydrodynamic computation of true or natural viscosities shows that ocean shear viscosity $\left(\eta_{\mathrm{G}}\right)$, compression viscosity $\left(\eta_{\mathrm{K}}\right)$, and extensional viscosity $\left(\eta_{\mathrm{E}}\right)$ are interrelated. There are no experimental methods available for the in situ measurement of these viscosities. Sound absorption coefficients $\left(\alpha_{\text {obs }}\right)$ allow to know the ultrasonic shear $\left(\eta_{\mathrm{UG}}\right)$, compression $\left(\eta_{\mathrm{UK}}\right)$, and longitudinal $\left(\eta_{\mathrm{L}}\right)$ viscosities, which decrease with increasing frequency and increase with increasing temperature, the flow activation energies having nearly equivalent values; pressure (depth) increase/decrease them at low/high frequencies. The viscosities $\eta^{*}{ }_{U G}, \eta^{*}{ }_{U K}, \eta_{L}^{*}$ are approached at about $1000 \mathrm{KHz}$. They decrease with temperature and pressure, and increase with salinity. The $\eta^{*}{ }_{\mathrm{UG}}$ becomes equal to the true shear viscosity $\eta_{\mathrm{G}}$ at the viscosity ratio $\delta=\eta_{\mathrm{UK}} / \eta_{\mathrm{UG}}=0$.
\end{abstract}

Keywords: Chemical relaxation, ocean rheology, sound absorption, ultrasonic viscosity, viscosity ratio.

\section{INTRODUCTION}

The continuum mechanic approach to ocean flow and deformation (ocean rheology) has been described elsewhere [1]. It may be summarized as follows:

Turbulent diffusion prevails in the ocean over molecular diffusion. Molecular diffusion in simple fluids, as the ocean is assumed to be, is isotropic because it develops at those very small scales where stratification plays no role in inhibiting the vertical motions.

The molecular diffusion mechanism of actual seawater is provided by the physical structural relaxation of clusters [2] which contain associations with weak (water-water) and strong (ion-water) bonds with their corresponding relaxation times [3].

The molecular horizontal momentum transport of seawater is the result of three contributions: shear $\left(\eta_{G}\right)$, extension $\left(\eta_{\mathrm{E}}\right)$, and compression $\left(\eta_{\mathrm{K}}\right)^{(!)}$flows [4] which are interrelated by Eq. (4) :

$$
\begin{aligned}
& \eta_{G}=\frac{-\sigma_{12}}{\frac{\partial u}{\partial z}}=\frac{-\sigma_{12}}{\frac{1}{\Delta z} \frac{\Delta x}{\Delta t}}=\frac{-\sigma_{12}}{\dot{\gamma}_{12}} \\
& \eta_{E}=\frac{-\left(\sigma_{11}-\sigma_{22}\right)}{\frac{1}{L} \frac{\Delta L}{\Delta t}}=\frac{-\left(\sigma_{11}-\sigma_{22}\right)}{\dot{\varepsilon}}=\frac{-N_{1}}{\dot{\varepsilon}} \\
& \eta_{K}=\frac{-\Delta p}{\frac{1}{\rho} \frac{\Delta \rho}{\Delta t}}=\frac{-\Delta p}{\frac{1}{V} \frac{\Delta V}{\Delta t}}=\frac{-\Delta p}{\dot{\chi}}
\end{aligned}
$$

*Address correspondence to this author at the Facultad de Ciencias del Mar, Campus Universitario de Tafira,35017 Las Palmas de Gran Canaria, Spain; E-mail: jaleman@dqui.ulpgc.es $\mathrm{h} \eta_{\mathrm{E}}+\mathrm{i} \eta_{\mathrm{G}}=\mathrm{j} \eta_{\mathrm{K}}$

(!) The term compression viscosity, internationally accepted [5], is used instead of the traditional bulk viscosity.

being $\sigma_{12},\left(\sigma_{11}-\sigma_{22}\right)=\mathrm{N}_{1}$, and $\Delta \mathrm{P}$, the shear, extensional, and compression stresses, respectively ; $\dot{\gamma}_{12}, \dot{\varepsilon}, \dot{\chi}$, are the shear, extensional, and compression deformation rates $; \mathrm{h}, \mathrm{i}, \mathrm{j}$ dimensionless parameters.

The effect of the system variables on these viscosities is as follows [1]:

$\eta_{\mathrm{G}}\left(1.0-1.5 \times 10^{-7}\right.$ dbar.s $)$ is independent of shear rate $\dot{\gamma}_{12}$ (Newton law, Eq. (1)), and $\eta_{\mathrm{K}}\left(2-4 \times 10^{-7}\right.$ dbar.s $)$ decreases with compression rate $\dot{\chi}\left(\mathrm{s}^{-1}\right)$.

Temperature (T) decreases $\eta_{\mathrm{G}}$ (Table 1) [1] and increases $\eta_{\mathrm{K}}$ (Table 2) [1]. The Arrhenius equation flow activation energies are positive and negative respectively: $\Delta \mathrm{E}_{\mathrm{G}}=4$ $\mathrm{kcal} / \mathrm{mol}$, and $\Delta \mathrm{E}_{\mathrm{K}}=-1 \mathrm{kcal} / \mathrm{mol}$.

Table 1. Ocean True Shear Viscosities

\begin{tabular}{|c|c|c|c|}
\hline $\begin{array}{c}\mathbf{Z} \\
(\mathbf{m})\end{array}$ & $\begin{array}{c}\mathbf{P} \\
\mathbf{d b a r}\end{array}$ & $\begin{array}{c}\mathbf{T} \\
{ }^{\mathbf{O}} \mathbf{C}\end{array}$ & $\begin{array}{c}\boldsymbol{\eta}_{G}{ }^{\mathbf{a}} \\
\mathbf{1 0}^{-7} \mathbf{d b a r} . \mathbf{s}\end{array}$ \\
\hline \hline 10 & 1 & 23.58 & 0.92 \\
\hline 100 & 10 & 16.69 & 1.01 \\
\hline 500 & 50 & 11.87 & 1.25 \\
\hline 1000 & 100 & 7.03 & 1.41 \\
\hline 1500 & 150 & 5.48 & 1.48 \\
\hline 20100 & 200 & 4.03 & 1.54 \\
\hline${ }^{a}$ Station B.
\end{tabular}

Salinity (S) increases both $\eta_{\mathrm{G}}$ and $\eta_{\mathrm{K}}$, but almost unnoticeably. 
Decreasing pressures $(\mathrm{P})$ (depth $\mathrm{z}$ ) reduce both $\eta_{\mathrm{G}}$ (Table 1) and $\eta_{\mathrm{K}}$ (Table 2) making the clusters to move vertically from a compressed (spheroidal) to an elongated (ellipsoidal) state.

Table 2. Ocean True Compression Viscosities

\begin{tabular}{|c|c|c|c|}
\hline $\begin{array}{c}\mathbf{Z} \\
(\mathbf{m})\end{array}$ & $\begin{array}{c}\boldsymbol{\eta}_{\mathbf{K}}{ }^{\mathbf{a}} \text { vs } \mathbf{z} \\
\mathbf{1 0}^{-7} \text { dbar.s }\end{array}$ & $\begin{array}{c}\boldsymbol{\eta}_{\mathbf{K}}^{\mathbf{b}}{ }^{\mathbf{1 0}} \mathbf{v} \mathbf{T} \\
\mathbf{1 0}^{-7} \mathbf{d b a r} . \mathbf{s}\end{array}$ & $\begin{array}{c}\mathbf{T} \\
{ }^{\mathbf{o}} \mathbf{C}\end{array}$ \\
\hline \hline 10 & 0.20 & 4.12 & 25 \\
\hline 100 & 0.40 & 4.06 & 20 \\
\hline 500 & 1.20 & 3.99 & 15 \\
\hline 1000 & 2.10 & 3.90 & 10 \\
\hline 1500 & 3.00 & 3.80 & 5 \\
\hline 2000 & 4.20 & ----- & \\
\hline${ }^{\mathrm{a}} \mathrm{T}=15^{\circ} \mathrm{C}, \dot{\chi}=4.5 \times 10^{9} \mathrm{~s}^{-1}, \delta=3.5$. & & \\
${ }^{\mathrm{b}} \chi=6.5 \times 10^{8} \mathrm{~s}^{-1}, \mathrm{z}=250 \mathrm{~m}, \delta=3.5$. &
\end{tabular}

There are no experimental techniques available to date to corroborate these results, but the needed suplementary experimental information may be obtained with in situ measurements of ocean sound absorption.

Recent developments of measurement techniques on molecular viscosity by ultrasound may be found in the literature [6-8]. Main studies on the ocean where devoted to oil slicks [9], red algae blooms [10] or the marine microlayer [11]. However to our knowledge there are no studies on the behavior of ultrasonic viscosity on the whole water column of the ocean. In section 3-a we formulate the expression of the ocean sound absorption coefficients, next in section 3-c we discuss the effect of temperature on the seawater viscosity ratio, we follow discussing the effects of pressure (depth), temperature and salinity on ultrasonic viscosities, finally we conclude summarizing the main findings.

\section{EXPERIMENTAL PROCEDURES}

Sound absorption coefficients $\left(\alpha_{\mathrm{abs}}\right)$ were measured with the method of sofar shots detonated at different ocean locations by [12] and references there on.
Viscosity ratios $(\delta)$ were deduced [1] from standard seawater shear viscosities [13] and ocean compressibility data [14].

\section{RESULTS AND DISCUSSION}

\subsection{Ocean Sound Absorption Coefficients}

The sound absorption coefficient $\left(\alpha_{\mathrm{i}}\right)$ for a single relaxation process obeys the equation [15]:

$\alpha_{i}=\frac{\pi \kappa_{i}}{\kappa_{0} c} \frac{f_{i} f^{2}}{f_{i}^{2}+f^{2}}$

where $\kappa_{\mathrm{o}}$ is the isothermal compressibility ( $\beta$ is the symbol commonly used for compressibility in ultrasonics), $\kappa_{\mathrm{i}}$ the chemical compressibility (Table 3) [16], c the sound velocity, $f$ the acoustic frequency, and $f_{i}$ the relaxation frequency which according to [17] is about $1 \mathrm{KHz}$ for boric acid $\left(\mathrm{B}(\mathrm{OH})_{3}\right)$ (in this frequency range the contribution of scattering of inhomogeneities in the index of refraction of the medium is a constant independent of frequency, and amounts to $10^{-6} \mathrm{~dB} / \mathrm{m}$ [18], about $10 \mathrm{KHz}$ for magnesium sulfate $\left(\mathrm{MgSO}_{4}\right)$, and about $1,000 \mathrm{KHz}$ for water $\left(\mathrm{H}_{2} 0\right)$.

Ocean sound absortion coefficients $\left(\alpha_{\mathrm{abs}}, \mathrm{dB} / \mathrm{m}\right)$ may be obtained from data of [12] (which are also used to asses the potential effects of suspended particles and gas bubbles) with the following equations [17]:

At salinity $\mathrm{S}=35$ [4] (A, B, C, $\mathrm{f}_{1}, \mathrm{f}_{2}$, being temperature, pressure, and salinity dependent parameters):

$\alpha_{o b s}=\frac{A f_{1} f^{2}}{f_{1}^{2}+f^{2}}+\frac{B f_{2} f^{2}}{f_{2}^{2}+f^{2}}+C f^{2}$

The first, second, and third terms of the right -hand side of Eq. (6) are related to the relaxation mechanisms of the $\mathrm{B}(\mathrm{OH})_{3}$ (carbonate modify it [4]), $\mathrm{MgSO}_{4}$, and $\mathrm{H}_{2} 0$, respectively. See Table 3 [16] in which are also shown the partial molal volume change of the solutes in sewawater $\left(\overline{\Delta \mathrm{V}^{*}}\right)$, and the partial molal compressibility of the solutes:

Table 3. Chemical Relaxation Mechanisms

\begin{tabular}{|c|c|c|c|c|}
\hline \multirow[t]{2}{*}{ Reaction } & \multicolumn{2}{|c|}{$\begin{array}{c}\overline{\Delta \mathrm{V}^{*}} \\
\mathbf{c m}^{3} \mathbf{m o l}^{-1}\end{array}$} & \multicolumn{2}{|c|}{$\begin{array}{c}\overline{\Delta \kappa^{*}} \\
\mathbf{c m}^{3} \mathbf{m o l}^{-1} \operatorname{bar}^{-1}\end{array}$} \\
\hline & $25^{\circ} \mathrm{C}$ & $5^{\circ} \mathrm{C}$ & $25^{\circ} \mathrm{C}$ & $5^{\circ} \mathrm{C}$ \\
\hline \multicolumn{5}{|l|}{ Acid-base equilibrium (non-electrolites): } \\
\hline Water $\quad \mathrm{H}_{2} \mathrm{O} \rightarrow \mathrm{H}^{+}+\mathrm{OH}^{-}$ & 18.0 & 19.5 & 3.15 & 4.73 \\
\hline Boric acid $\mathrm{B}(\mathrm{OH})_{3}+\mathrm{H}_{2} \mathrm{O} \rightarrow \mathrm{H}^{+}+\mathrm{B}(\mathrm{OH})_{4}^{-}$ & 25.7 & 28.0 & 1.93 & 2.79 \\
\hline Carbonic acid $\mathrm{CO}_{2}+\mathrm{H}_{2} \mathrm{O} \rightarrow \mathrm{CO}_{3} \mathrm{H}_{2}$ & 22.6 & 24.7 & 1.90 & 3.51 \\
\hline $\mathrm{CO}_{3} \mathrm{H}^{-} \rightarrow \mathrm{H}^{-} \mathrm{CO}_{3}^{2-}$ & ----- & ----- & ---- & ----- \\
\hline Ion-pair equilibrium: & & & & \\
\hline $\mathrm{MgSO}_{4}(\mathrm{aq}) \rightarrow \mathrm{Mg}^{2+}(\mathrm{aq})+\mathrm{SO}_{4}^{2-}(\mathrm{aq})$ & 7.2 & ------- & 1.7 & ------. \\
\hline
\end{tabular}




$$
\overline{\Delta \kappa^{*}}=\overline{-\Delta \mathrm{V}^{*}} / \Delta \mathrm{P}
$$

At $\mathrm{S}=35-37$ and frequency $\mathrm{f}=2-25 \mathrm{KHz}[19]$ :

$\alpha_{o b s}=8.6866\left(\frac{2.34 \times 10^{-6} S f_{T} f^{2}}{f_{T}^{2}+f^{2}}+\frac{3.38 \times 10^{-6} f^{2}}{f_{T}}\right)\left(1-6.54 \times 10^{-4} P\right)$

with the frequencies $\mathrm{f}$ and $\mathrm{f}_{\mathrm{T}}=21.9 \times 10^{6-1520 /(\mathrm{T}+273)}$ in $\mathrm{KHz}$, $\mathrm{T}^{\circ} \mathrm{C}, \mathrm{P}$ in atmosphere, and the factor 8.6866 to convert nepers $/ \mathrm{m}$ into $\mathrm{dB} / \mathrm{m}$.

Seawater $\alpha_{o b s}$ (Fig. 1) behaves differently at frequencies of the order of the $\mathrm{H}_{2} 0$ relaxation one $(500-1,000 \mathrm{KHz})$, and shows a change of slope at about $15^{\circ} \mathrm{C}$. The molecular

\section{(a)}

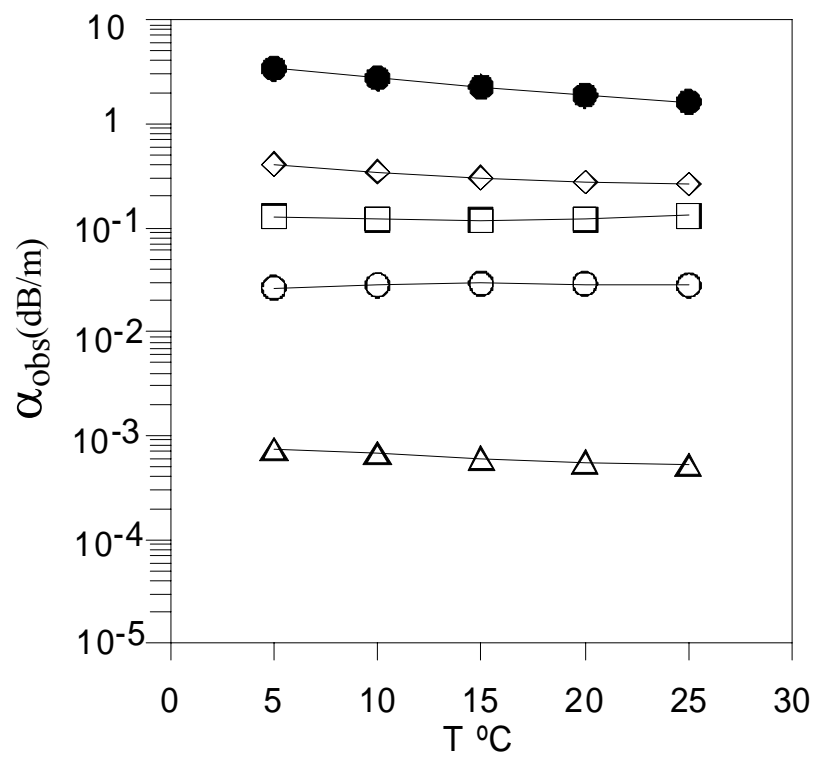

(c) structure of pure water is [20] (Fig. 1c): hexagonal (ice crystals) below $0^{\circ} \mathrm{C}$, tetrahedral (pentamer) above $5^{\circ} \mathrm{C}$, chain like (trimer) at about $27^{\circ} \mathrm{C}$, more than $10 \%$ of the water molecules have changed their tetrahedral structure to the chain one above $30^{\circ} \mathrm{C}$.

The ocean sound absorption coefficient is related to the ultrasonic shear $\left(\eta_{\text {UG }}\right)$ and compression $\left(\eta_{\text {UK }}\right)$ viscosities by the equation [17]:

$$
\alpha_{\text {theor }}=\frac{16 \pi^{2} f^{2}}{3 \rho c^{3}}\left(\eta_{U G}+\frac{3}{4} \eta_{U K}\right)=\frac{16 \pi^{2} f^{2}}{3 \rho c^{3}} \eta_{U G}+\frac{4 \pi^{2} f^{2}}{\rho c^{3}} \eta_{U K}
$$

(b)

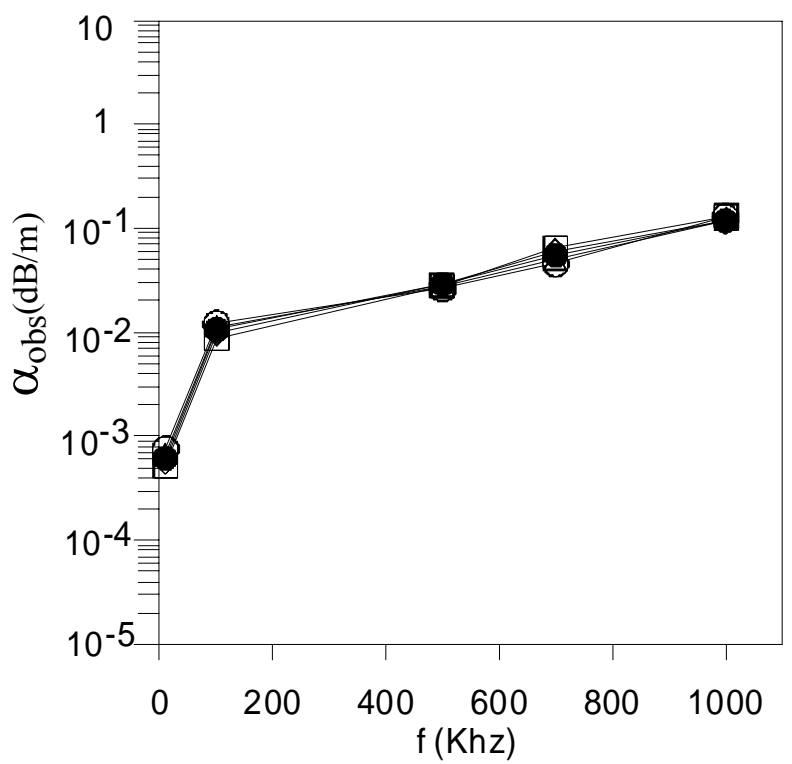

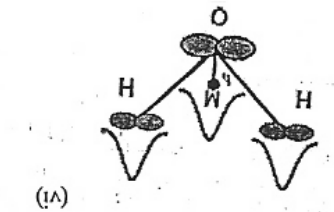


in which $\mathrm{f}$ is the frequency in $\mathrm{Hz}$, and the viscosities expressed in poises, the density in $\mathrm{g} / \mathrm{cm}^{3}$, and the sound velocity $\mathrm{c}$ in $\mathrm{cm} / \mathrm{s}$ calculated with the algorithm described by [17].

The first term of Eq. (8) is the absorption coefficient $\alpha_{\text {class }}$ in the low frequency limit, i.e., the shear viscous loss [4]:

$$
\alpha_{\text {class }}=\frac{16 \pi^{2} f^{2}}{3 \rho c^{3}} \eta_{U G}
$$

\subsection{Viscosity Ratio}

The shear and compression viscosities are interrelated by the equation [1]:

$\delta=\eta_{\mathrm{UK}} / \eta_{\mathrm{UG}}$

Measurement of this dimensionless ratio provide $\delta=2.81$ for seawater [18]. Seawater $\delta$ values at $\mathrm{S}=35-37, \mathrm{~T}=5^{\circ} \mathrm{C}$ $25^{\circ} \mathrm{C}, \mathrm{P}=1-2000 \mathrm{dbar}$, may be deduced as in [1].

Fig. (2a) is a typical example at $\mathrm{S}=35$ since: i) the $\eta_{\mathrm{G}}$ used are for standard seawater [13], ii) the effect of $\mathrm{S}$ on both $\eta_{\mathrm{G}}$ and $\eta_{\mathrm{K}}$ are almost unnoticeable [1], iii) Eq. (6) used to compute the sound absorption coefficients $\left(\alpha_{\text {obs }}\right)$ is valid only for $S=35$ [17]. As may be observed the plots are nearly straight lines and $\delta$ increases with increasing depth $(\mathrm{z})$ and decreasing compression rate $(\dot{\chi})$.

The effect of temperature on the seawater viscosity ratio (Fig. 2b) shows a different slope below and above $15^{\circ} \mathrm{C}$ [1], what possibly is due to the fact that seawater is a dilute polymeric system consisting of 6-60 water molecules with an ion in the center (solvation shell) (Fig. 1c). Under the pressure of sound waves the relaxation mechanism is a chemical association-dissociation reaction [15] giving rise to a large volume change upon ionization (Table 3, [16]). Most seawater cations are in a $99 \%$ dissociated state, while magnesium sulfate $\left(\mathrm{MgSO}_{4}\right)$ is only $78.5 \%$ dissociated (Table 4) [21]. As the temperature increases a decrease of both the partial molal volume change $\left(\overline{\Delta \mathrm{V}^{*}}\right)$ and the partial molal compressibility $\left(\overline{\Delta \kappa^{*}}\right.$ ) occurs (Table 3 ). The corresponding cluster structure expands decreasing the volume deformation $(\chi=(\Delta V / V))[1]$ The final result is an increase in compression viscosity and viscosity ratio (Eqs. (3) and 10)).

The viscosity ratio $\delta$ of pure water has been measured [4] to be $2.68-2.75$ and is almost independent of depth (pressure), while it decreases slightly at all temperatures [4, 22] and, at frequencies of the order of $\mathrm{GHz}$, decreases steeply below $15^{\circ} \mathrm{C}$ (Figure 8 of [23]); compare with Fig. (1a) and Eq. (11).

\subsection{Ultrasonic Viscosities}

The ultrasonic compression viscosity $\left(\eta_{\mathrm{UK}}\right)$ is [4]:

$\eta_{U K}=\frac{4}{3} \eta_{U G}\left(\frac{\alpha_{o b s}-\alpha_{\text {class }}}{\alpha_{\text {class }}}\right)$

Substituting in Eq.(11) the Eqs.(6-6a, 9, 10) results:

$$
\eta_{U K}=\delta \cdot \eta_{U G}=\frac{4}{3} \eta_{U G}\left(\frac{\alpha_{o b s}}{\alpha_{\text {class }}}-1\right)
$$

which allows to find the ultrasonic shear viscosity ( $\left.\eta_{\mathrm{UG}}\right)$ as follows (the factor 0.25 comes from $0.25=(4 / 3) /(16 / 3)$ ):

$$
\delta \cdot \eta_{U G}=\frac{4}{3} \eta_{U G} \cdot \frac{\alpha_{o b s}}{\frac{16 \pi^{2} f^{2}}{3 \rho c^{3}} \eta_{U G}}-\frac{4}{3} \eta_{U G}=\frac{0.25 \cdot \alpha_{o b s} \cdot \rho c^{3}}{\pi^{2} f^{2}}-\frac{4}{3} \eta_{U G}
$$

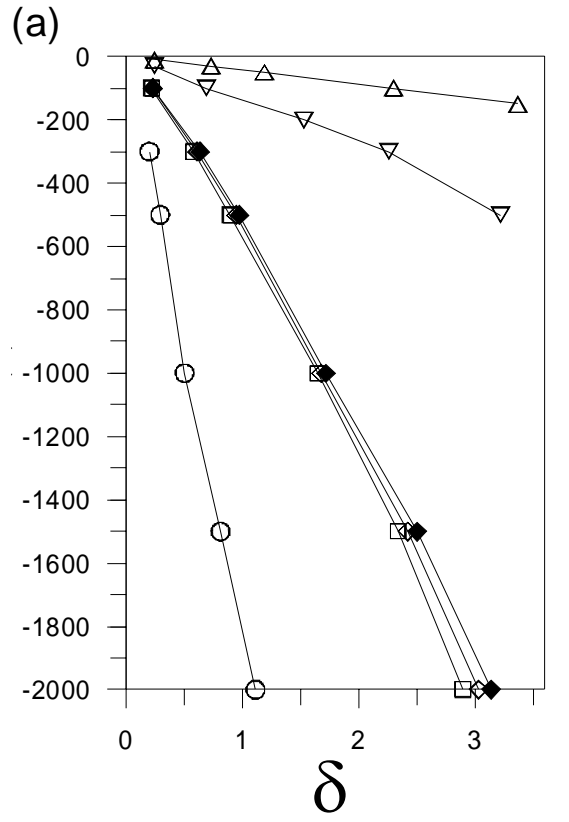

(b)

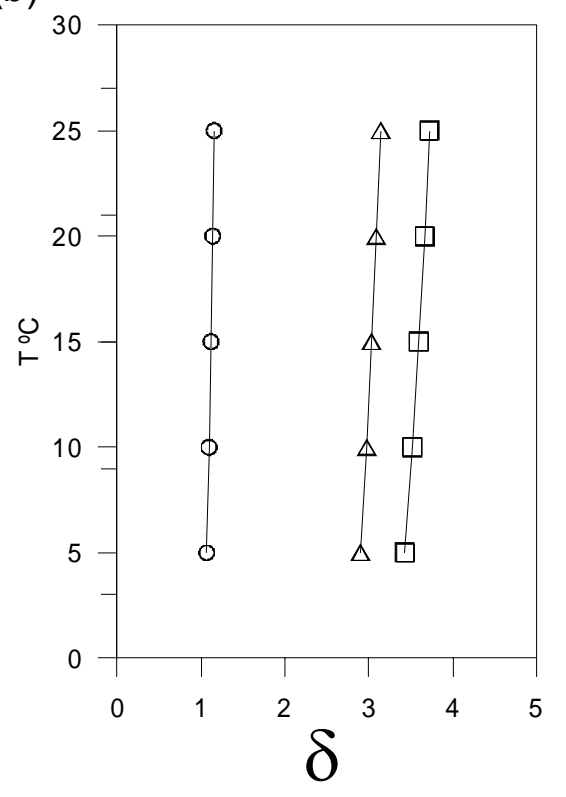

Fig. (2). Seawater viscosity ratio $(\delta)\left(\right.$ a) at $\mathrm{T}=15^{\circ} \mathrm{C}, \mathrm{S}=35$, as a function of depth (z) and different compression rates $(\dot{\chi}):(\Delta) 4.2 \mathrm{x} 10^{8} \mathrm{~s}^{-1}$, (V) $1.210^{9} \mathrm{~s}^{-1},(\diamond) 4.25 \times 10^{9} \mathrm{~s}^{-1},\left(\diamond=25^{\circ} \mathrm{C}, \square=5^{\circ} \mathrm{C}\right),(\circ) 1.1 \times 10^{10} \mathrm{~s}^{-1}$. (b) as a function of temperature at $\mathrm{S}=35, \mathrm{z}=2,000 \mathrm{~m},(\Delta) \dot{\chi}=4.2$ $\mathrm{x} 10^{9} \mathrm{~s}^{-1},(\circ) \dot{\chi}=1.1 \times 10^{10} \mathrm{~s}^{-1},(\square) 1.16 \times 10^{9} \mathrm{~s}^{-1}(\mathrm{z}=500 \mathrm{~m})$. 
Table 4. Dissociation States of Seawater Salts

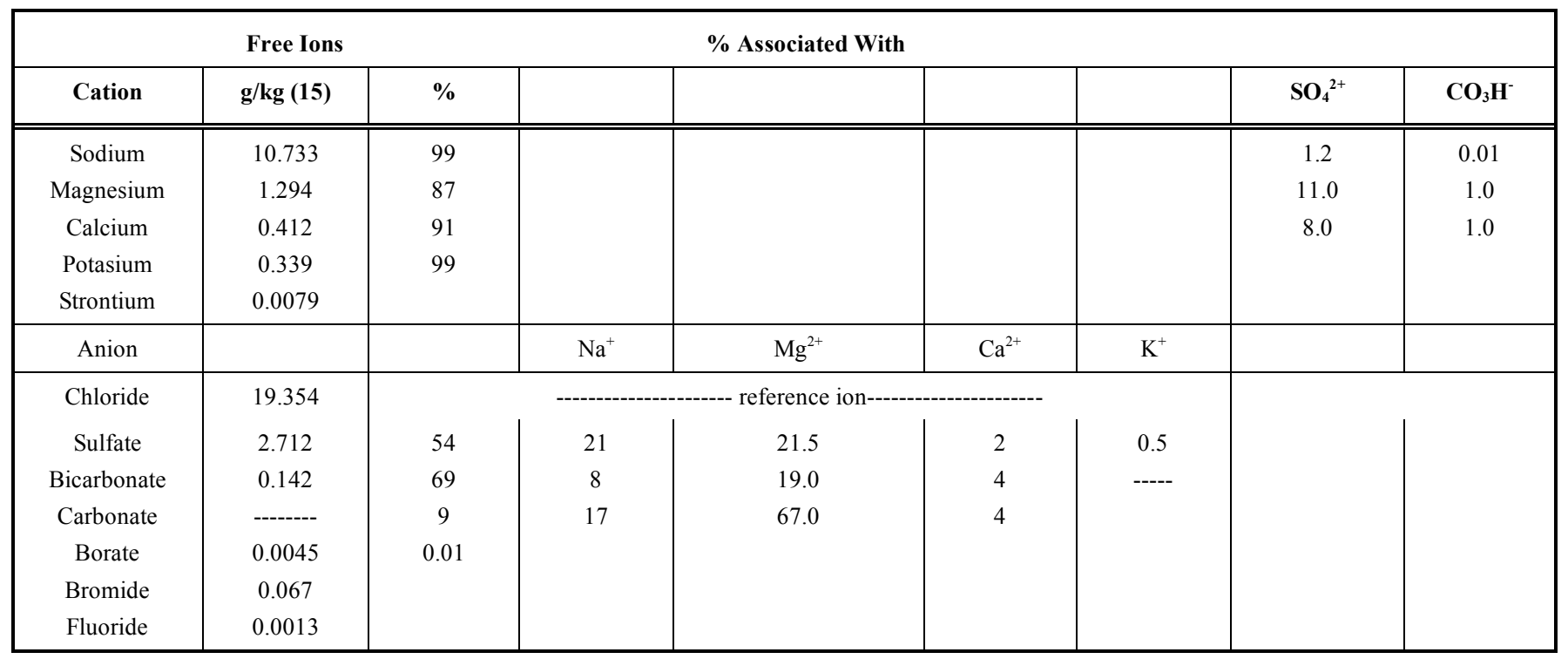

Therefore

$\delta \cdot \eta_{U G}+\frac{4}{3} \eta_{U G}=\left(\delta+\frac{4}{3}\right) \eta_{U G}=\frac{0.25 \cdot \alpha_{o b s} \cdot \rho c^{3}}{\pi^{2} f^{2}}$

and (using the factor $10^{-2}$ to have the results with units $10^{-7}$ dbar.s) the ultrasonic shear viscosity is:

$$
\eta_{U G}=\frac{0.25 \cdot 10^{-2} \cdot \alpha_{o b s} \cdot \rho c^{3}}{\pi^{2} f^{2}} \cdot \frac{1}{\delta+\frac{4}{3}}
$$

which at $\delta=0$ is equivalent to Eq. (9) (see also Fig. 3d).

The ultrasonic compression viscosity $(\eta \mathrm{UK})$ is obtained then from Eq. (12):

$$
\eta_{U K}=\delta \cdot \eta_{U G}=\frac{0.25 \cdot 10^{-2} \cdot \alpha_{o b s} \cdot \rho c^{3}}{\pi^{2} f^{2}} \cdot \frac{\delta}{\delta+\frac{4}{3}}
$$

which at $\delta=0$ becomes $\eta_{\mathrm{UK}}=0$ (Fig. 3f).

The longitudinal viscosity $\left(\eta_{L}\right)$ may be estimated as [18]:

$\eta_{L}=\frac{4}{3} \eta_{U G}+\eta_{U K}$

Fig. (3a, c, e, g), show that the three viscosities $\eta_{\text {UG }}, \eta$ UK, $\eta$ L decrease with increasing frequency, becoming independent of it at about $20 \mathrm{KHz}$ (Fig. 3b). The viscosities $\eta_{\text {UG, }}^{*} \boldsymbol{\eta}^{*}{ }_{\mathbf{U K}}, \eta_{\mathbf{L}}$, shown in Fig. $(\mathbf{3 d}, \mathbf{f}, \mathbf{h})$, are approached at the $\mathrm{H}_{2} 0$ relaxation frequency $(1,000 \mathrm{KHz})$, as shown in Fig. (3c, $\mathbf{e}, \mathbf{g})$.

As $\delta$ decreases: [1].

$\eta_{\text {UG }}^{*}$ increases towards the true viscosity $\eta_{G}($ Table 1) $\eta_{\text {UK }}^{*}$ decreases towards $\eta^{*}$ UK $=0$. It also decreases with temperature: note that this is contrary to what happens with continuum mechanics $\eta_{\mathrm{K}}$ values (Eq. 3) which increase with temperature (Table 2) [1]. It is due to fact that the effect of temperature is different on the chemical asociationdissociation relaxation than on the physical cluster structure relaxation. The activationn energies $(\Delta \mathrm{E})$ computed with Arrhenius equation [1] have nearly equivalent values (shear $\Delta \mathrm{E}_{\mathrm{UG}}=2.46 \mathrm{kcal} / \mathrm{mol}$, compression $\Delta \mathrm{E}_{\mathrm{UK}}=1.80 \mathrm{kcal} / \mathrm{mol}$, longitudinal $\Delta \mathrm{E}_{\mathrm{L}}=2.10 \mathrm{kcal} / \mathrm{mol}$ ).

$\eta_{L}^{*}$ is almost constant suggesting that (Eqs. (17) and (4)):

$\eta_{L}^{*(\delta \rightarrow 0)}=\frac{4}{3} \eta_{U G}^{*(\delta \rightarrow 0)}+\eta_{U K}^{*(\delta \rightarrow 0)} \approx h \eta_{E}=-i \eta_{G}+j \eta_{K}$

It shows the effect on $\eta_{\mathrm{E}}$ of the strength of the cluster hydrogen bonds (which are, for example, stronger for $\mathrm{Na}^{+}$ and weaker for $\mathrm{Cl}^{-}$), and that the clusters are more compacted at large depths.

Fig. (4a) shows that as the temperature increases $\eta_{\text {UG }}, \eta$ $\mathrm{UK}, \eta_{\mathrm{L}}$ increase at low frequencies up to $15^{\circ} \mathrm{C}$ and decrease at higher temperatures for all frequencies. It is the result of the combined effects of the sound velocity c (increase with increasing temperature [17]), the sound absorption coefficient $\alpha_{\text {obs }}$ (Fig. 1), and the viscosity ratio $\delta$ (Fig. 2b). $\eta_{\text {UG }}^{*}, \eta_{\text {UK }}^{*}, \eta_{\text {L }}^{*}$ (Fig. 4b) decreases with temperature.

The effect of pressure (depth) is to increase $\eta_{\mathrm{UG}}, \eta_{\mathrm{UK}}$, and $\eta_{\mathrm{L}}$ (Fig. 4c). The viscosities $\eta_{\text {UG }}{ }^{*}, \eta_{\text {UK }}{ }^{*}$, and $\eta_{L}^{*}$ above $1,000 \mathrm{KHz}$ (Fig. 4d) decrease since increasing depth (P) decrease $\overline{\Delta \kappa^{*}}$ (equation 7).

The effect of salinity (S) on the ultrasonic viscosities can be known replacing Eq. (6) by Eq. (6a) in Eq. (15). Fig. (4e, f) show that the salinity increases the three viscosities since increasing salinity decreases $\overline{\Delta \mathrm{V}^{*}}$ and $\overline{\Delta \kappa^{*}}$. 
(a)

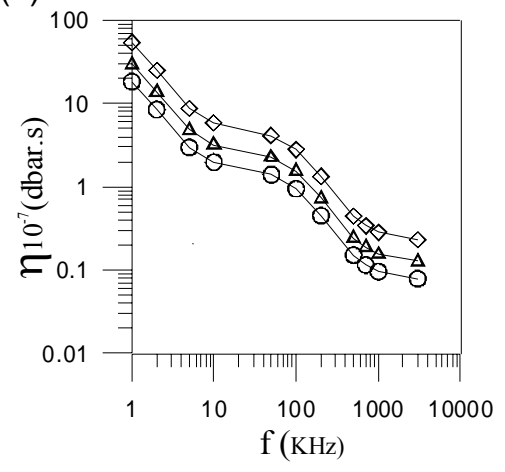

(c)

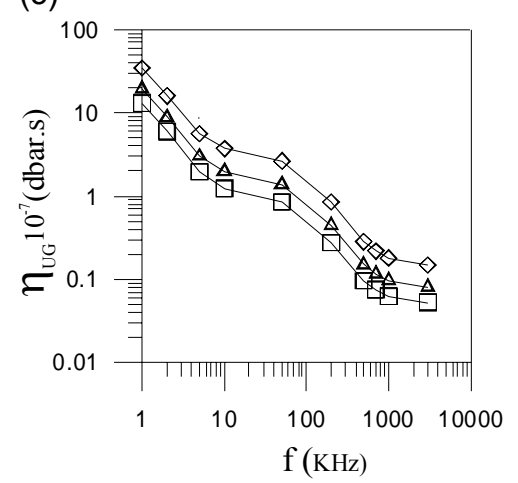

(e)

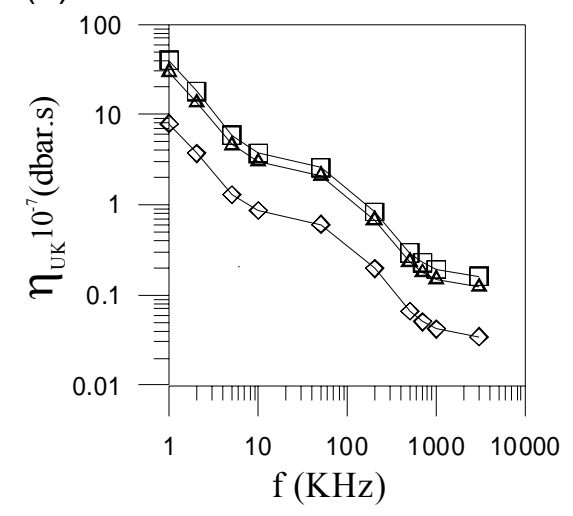

(g)

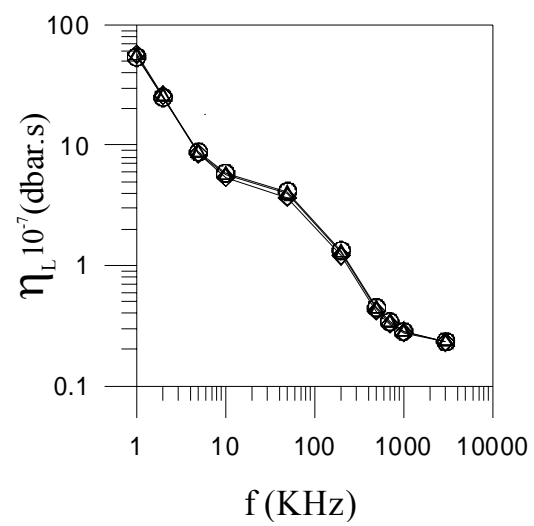

(b)

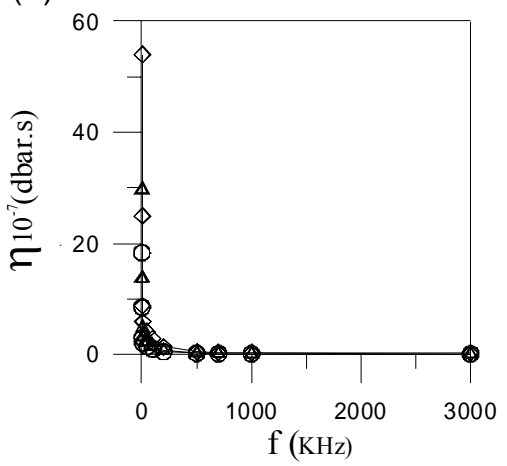

(d)

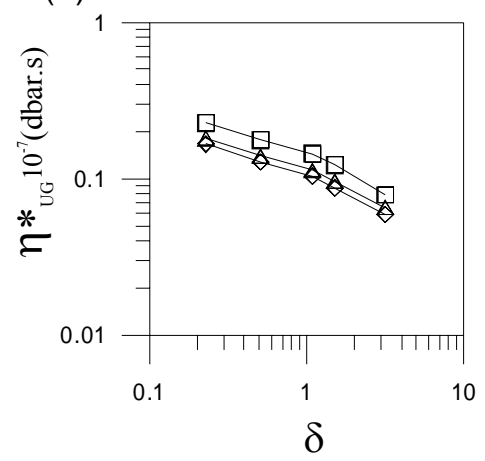

(f)

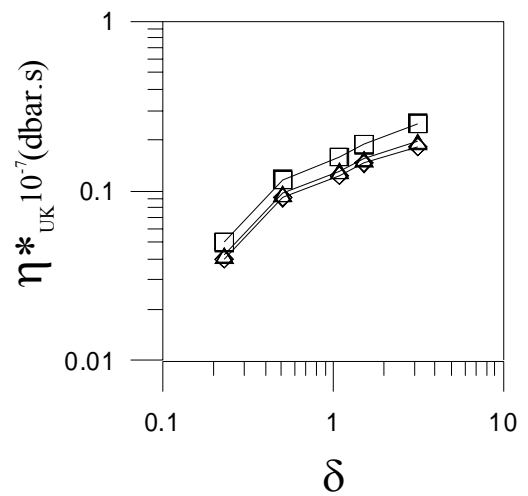

(h)

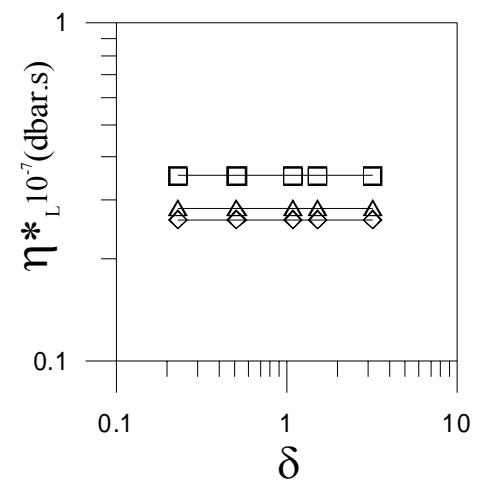

Fig. (3). Ultrasonic viscosities at $\mathrm{T}=15^{\circ} \mathrm{C}, \mathrm{S}=35, \delta=1.52$, as a function of frequency: (a) ((b) decimal plot) $(\circ) \eta_{\mathrm{UG}},(\Delta) \eta_{\mathrm{UK}},(\diamond) \eta_{\mathrm{L}}$, and at different viscosity ratios $\delta\left((\mathrm{o}) 80.23,(\Delta) 1.52,(\diamond) 3.03\right.$, (c) $\eta_{\mathrm{UG}},(\mathbf{e}) \eta^{*}{ }_{\mathrm{UK}},(\mathbf{g}) \eta^{*} \mathrm{~L}$. As a function of $\delta$ at frequency $\mathrm{f}_{\mathrm{i}}=1,000 \mathrm{KHz}$ and different temperatures $\left.(\square) 5^{\circ} \mathrm{C},(\Delta) 15^{\circ} \mathrm{C},(\diamond) 25^{\circ} \mathrm{C}\right) ;(\mathbf{d}) \eta^{*}{ }_{\mathrm{UG}},(\mathbf{f}) \eta^{*}{ }_{\mathrm{UK}},(\mathbf{h}) \eta^{*}{ }_{\mathrm{L}}$. 
(a)

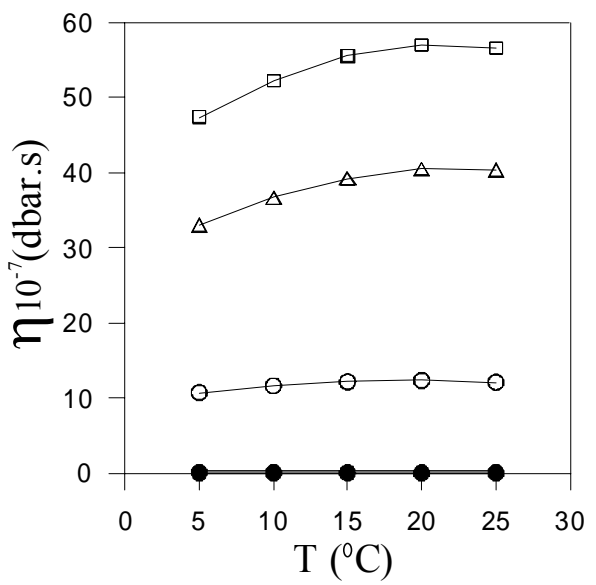

(c)

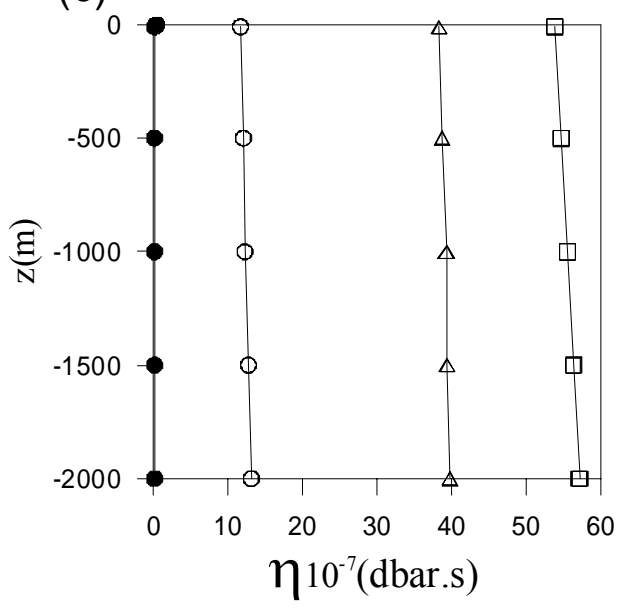

(e)

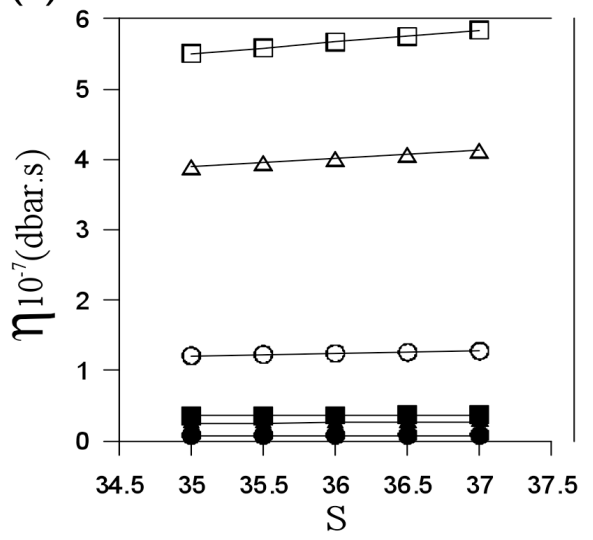

(b)

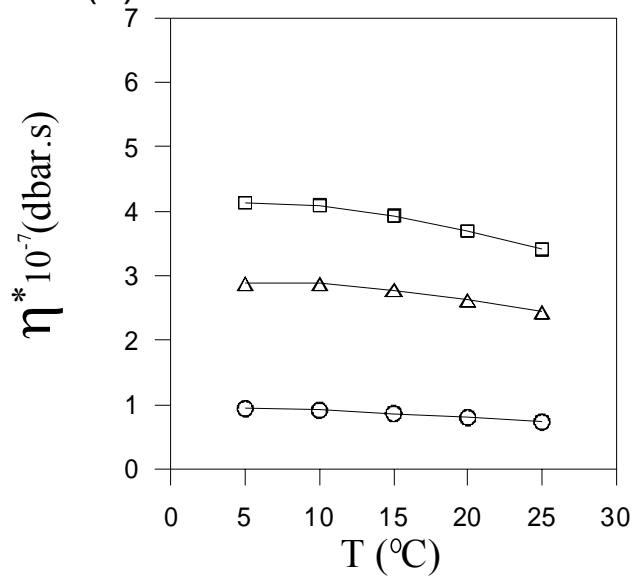

(d)

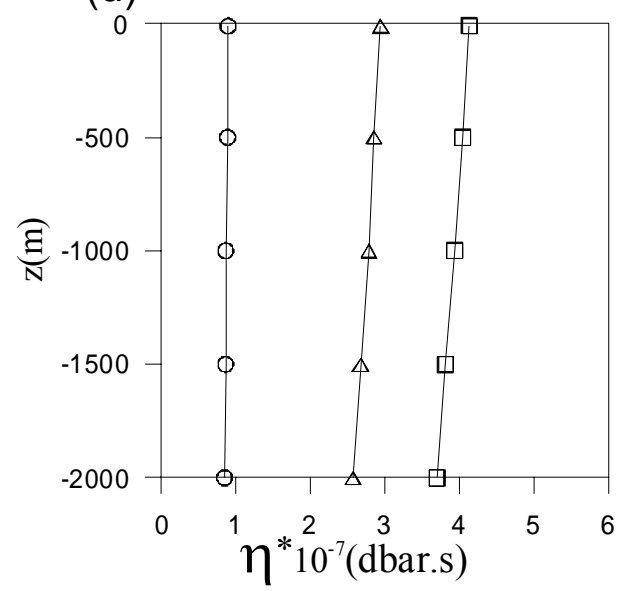

(f)

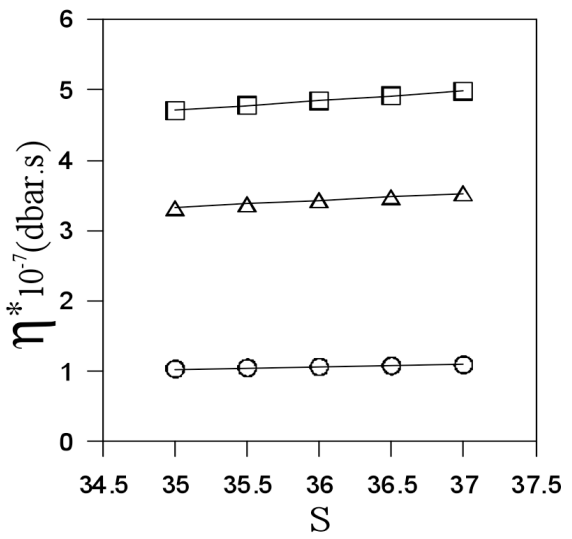

Fig. (4). Effect of temperature at $S=35, z=1,000 \mathrm{~m}, \delta=3.2$, on (a) (०) $\eta_{\mathrm{UG}},(\Delta) \eta_{\mathrm{UK}},(\square) \eta_{\mathrm{L}}$, at frequency (white symbols) $1 \mathrm{KHz}$, and (•) $700 \mathrm{KHz} .(\mathbf{b})(\circ) \eta_{\mathrm{UG}}^{*},(\Delta) \eta^{*}{ }_{\mathrm{UK}},(\square) \eta_{\mathrm{L}}{ }^{*}\left(f_{\mathrm{i}}=1,000 \mathrm{KHz}\right)$. Effect of depth (z) at $\mathrm{T}=15^{\circ} \mathrm{C}, \mathrm{S}=35, \delta=3.2$, and frequency (white symbols) 1 $\mathrm{KHz}$, and $(\bullet) 700 \mathrm{KHz}$ : on (c) (०) $\eta_{\mathrm{UG}},(\Delta) \eta_{\mathrm{UK}},(\square) \eta_{\mathrm{L}}((\bullet), \square$, at $700 \mathrm{KHz})$; (d) (०) $\eta^{*} \mathrm{UG},(\Delta) \eta_{\mathrm{UK}}{ }^{*},(\square) \eta_{\mathrm{L}}\left(\mathrm{f}_{\mathrm{i}}=1,000 \mathrm{KHZ}\right)$. Effect of salinity $(\mathrm{S})$ at $\mathrm{T}=15^{\circ} \mathrm{C}, \mathrm{z}=1,000 \mathrm{~m}, \delta=3.21$, and $\mathrm{f}=10 \mathrm{KHz}:(\mathbf{e})(\circ) \eta_{\mathrm{UG}},(\diamond) \eta_{\mathrm{UK}},(\square) \eta_{\mathrm{L}}((\bullet), \nabla, \boldsymbol{\square}$, at $700 \mathrm{KHz}) ;(\mathbf{f})$ at $\mathrm{f}_{\mathrm{i}}=1,000 \mathrm{KHz}$ (०) $\eta^{*}{ }_{U G},(\Delta) \eta^{*}{ }_{U K},(\square) \eta^{*}$ L.

\section{CONCLUSIONS}

Seawater is a system which contains compressed hydrogen-bonded reversible ion networks (clusters) suspended in water oligomers. The molecular behavior of this system may be interpreted with two different approaches. The continuum mechanics with which the shear, extensional, and compression viscosities may be evaluated [1]. Ultrasonic measurements which show that ultrasonic shear, ultrasonic compression, and longitudinal viscosities decrease with frequency, increase/decrease with temperature, 
and the pressure (depth) increase/decrease them at low and high frequencies, respectively. At the lower viscosity ratio $(\delta)$ the ultrasonic shear viscosity is similar to the continuum mechanics one.

\section{ACKNOWLEDGMENTS}

We thanks to J.L. Pelegri, co-author of the Ocean rheology (2006) article, for useful discussions. Partial support for this work has been provided by the Spanish government through project COUPLING (CTM200806343C02-01/ANT).

\section{REFERENCES}

[1] Aleman JV, Pelegrí JL, Sangrà P. Ocean rheology. J NonNewtonian Fluid Mech 2006; 133: 121-31.

[2] Stace A. Cluster solutions. Science 2001; 294: 1292-3.

[3] Wang XB, Yang X, Nicholas JB, Wang LS. Bulk-like features in the photoemission spectra of hydrated double charged anion clusters. Science 2001; 294: 1322-5.

[4] Litovitz TA, Davis CM. In: Mason WP, Ed. Structural and shear relaxation in liquids, in physical acoustics. New York: Academic Press 1965; vol. IIA.

[5] Kaye A, Stepto RF, Work WJ, Aleman JV, Malkin AY. Definitions of terms relating to the non-ultimate properties of polymers. Pure Appl Chem 1998; 70: 701-54.

[6] Wygant IO, Kupnik M, Windsor JC, et al. $50 \mathrm{kHz}$ Capacitive micromachined ultrasonic transducers for generation of highly directional sound with parametric arrays. IEEE Trans Ultrason Ferroelectr Freq Control 2009; 56(1): 193-203.

[7] Stephens DN, Cannata J, Liu R, et al. Multifunctional catheters combining intracardiac ultrasound imaging and electrophysiology sensing. IEEE Trans Ultrason Ferroelectr Freq Control 2008; 55(7): 1570-81.

[8] Huang Y, Zhang X, Haeggstrom EO, Ergun AS, Cheng C-H, Khuri-Yakub BT. Capacitive micromachined ultrasonic transducers (CMUTs) with isolocation posts. Ultrasonics 2008; 48: 74-81.

[9] Scott JC. Ocean surface slicks-pollution, productivity, climate andlife-saving. Geoscience and Remote Sensing Symposium, 1999.
IGARSS '99 Proceedings. IEEE 1999 International 1999; vol 3: pp. 1463-8.

[10] Zhou C, Ma H. Ultrasonic degradation of polysaccharide from a red algae (Porphyra yezoensis). J Agric Food Chem 2006; 54 (6): 2223-8.

[11] Cinbis C, Despaux G, Robert L, Chou C-H, Khuri-Yakub BT. Ultrasonic in-situ measurement of the marine microlayer. Ultrason Symp Proc IEEE 1990; 2: 1057-60.

[12] Thorp WH. Deep ocean sound absorption in the sub- and lowkiilocycle-per-second region. J Acoust Soc Am 1965; 38: 648-54.

[13] Stanley EM, Batten RC. Viscosity of seawater at moderate temperatures and pressures. J Geophys Res 1969; 74: 3415-20.

[14] Sun S, Bleck R, Rooth C, Dikowicz J, Chassignet E, Killworth P Inclusion of thermobaricity in isopicnic-coordinate ocean models. J Phys Oceanogr 1999; 29: 2719-29.

[15] Fisher FH, Simmons VP. Sound absorption in water. J Acoust Soc Am 1977; 62: 552-64.

[16] Millero FJ. In: Riley JP, Chester R, Eds. Chemical oceanography. USA: Academic Press 1983; vol. 8.

[17] Urick RJ. Principles of underwater sound. New York: McGrawHill 1975.

[18] Kinsler LE, Frey AL, Coppens AB, Sanders JV. Fundamentals of acoustics. New York: Wiley \& Sons 1982.

[19] Schulkin M, Marsk HW. Sound absorption in water. J Acoust Soc Am 1962; 34: 864

[20] Wernet $\mathrm{Ph}$, Nordlun D, Berghman U, et al. The structure of the first coordination shell in liquid water. Science 2004; 304: 995-9.

[21] Garrels RM, Thompson ME. A chemical model of seawater at $25^{\circ} \mathrm{C}$ and one atmosphere total pressure. Am J Sci 1962; 260: 57-66.

[22] Rouch J, Lai CC, Chen H. Brillouin scattering studies of normal and supercooled water. J Chem Phys 1976; 65: 4016-21.

[23] Xu J, Ren XR, Gong W, Dai R, Liu D. Measurement of the bulk viscosity of liquid by Brillouin scattering. Appl Opt 2003; 42: 6704-9.

[24] Whitfield M. In: Riley JP, Skirrow G, Eds. Chemical oceanography, $2^{\text {nd }}$ ed. USA: Academic Press 1975; vol. 2.

[25] Niesar U, Corongiu G, Clementi E, Kneller GR, Braattacharya DK. Molecular dynamics simulation of liquid water using the NCC ab initio potential. J Phys Chem 1990; 94: 7949-56.

[26] Fanourgakis GS, Xantheas SS. The flexible, polarizable, Thole Type, interaction potential for water (TTM2-F) revisited. J Chem Phys 2006; 110: 4100-6. 